\title{
Hydrological Variability in the Arid Region of Northwest China from 2002 to 2013
}

\author{
Yanping Cao, ${ }^{1}$ Zhuotong Nan $\mathbb{D D}^{2,3}{ }^{2, G u o d o n g ~ C h e n g, ~}{ }^{4}$ and Ling Zhang ${ }^{4}$ \\ ${ }^{1}$ College of Environment and Planning, Henan University, Kaifeng 475004, China \\ ${ }^{2}$ Key Laboratory of Virtual Geographic Environment of Ministry of Education, Nanjing Normal University, Nanjing 210023, China \\ ${ }^{3}$ Jiangsu Center for Collaborative Innovation in Geographical Information Resource Development and Application, \\ Nanjing 210023, China \\ ${ }^{4}$ Northwest Institute of Eco-Environment and Resources, Chinese Academy of Sciences, Lanzhou 730000, China
}

Correspondence should be addressed to Zhuotong Nan; nanzt@njnu.edu.cn

Received 17 August 2017; Revised 18 January 2018; Accepted 19 February 2018; Published 29 March 2018

Academic Editor: Brian R. Nelson

Copyright (C) 2018 Yanping Cao et al. This is an open access article distributed under the Creative Commons Attribution License, which permits unrestricted use, distribution, and reproduction in any medium, provided the original work is properly cited.

\begin{abstract}
The arid region of Northwest China (ANC) has a distinct and fragile inland water cycle. This study examined the hydrological variations in ANC and its three subregions from August 2002 to December 2013 by integrating terrestrial water storage (TWS) anomaly data derived from the Gravity Recovery and Climate Experiment (GRACE) satellite, soil moisture data modeled by the Global Land Data Assimilation System, and passive microwave snow water equivalent data. The results show that the TWS in ANC increased at a rate of $1.7 \mathrm{~mm} / \mathrm{a}$ over the past decade, which consisted of an increasing trend of precipitation $(0.12 \mathrm{~mm} / \mathrm{a})$. Spatially, in the northern ANC, TWS exhibited a significant decreasing trend of $-3.64 \mathrm{~mm} / \mathrm{a}(p<0.05)$ as a result of reduced rainfall, increased glacial meltwater draining away from the mountains, and intensified human activities. The TWS in southern and eastern ANC increased at a rate of $2.14(p=0.10)$ and $1.63(p<0.01) \mathrm{mm} / \mathrm{a}$, respectively. In addition to increasing precipitation and temperature, decreasing potential evapotranspiration in Southern Xinjiang and expanding human activities in Hexi-Alashan together led to an overall increase in TWS. Increased glacier meltwater and permafrost degradation in response to climate warming may also affect the regional TWS balance. The variations in soil moisture, groundwater, and surface water accounted for the majority of the TWS anomalies in southern and eastern ANC. The proposed remote sensing approach combining multiple data sources proved applicable and useful to understand the spatiotemporal characteristics of hydrological variability in a large area of arid land without the need for field observations.
\end{abstract}

\section{Introduction}

Climate change together with human activities (e.g., land reclamation and agricultural irrigation) can result in large variations in hydrological regimes and increase the severity of hydrological and water resources issues, particularly in areas such as the arid region of Northwest China (ANC) $[1,2]$. Terrestrial water storage (TWS) is a vital component in the hydrological and biogeochemical cycles [3] and a key factor that influences ecological security [4] and distribution of human settlements. The TWS is sensitive to climate variability, especially in arid regions characterized by a severe lack of available water and high potential evapotranspiration (ET). The TWS anomaly (TWSA) in the large arid areas is generally hard to detect due to the lack of effective monitoring methods. The Gravity Recovery and Climate Experiment (GRACE) satellite has provided a new approach for monitoring TWSA over large areas at multiple time scales. The GRACE data have been successfully used to explore regional-scale terrestrial water variabilities across the world, such as in Amazon [5], Illinois [6], and the High Plains Aquifer of the USA [7]. These previous studies suggest that GRACE data can be effectively used to detect TWSA at a regional scale.

The ANC in this study is one of the largest arid regions in the world and is extremely vulnerable to water scarcity [8]. The characteristics of water resources in the ANC differ from other regions of China, representative for other arid 
regions across the world [8]. Glaciers and snowmelt on high mountains, precipitation in middle mountain regions, and fissure water in low mountain areas constitute the majority of water sources in ANC. The fragile and vulnerable water resources in ANC have strongly affected the local economic development [9]. In addition, many extreme hydrological events have occurred in this region [10]. Thus, it is imperative to study the characteristics of hydrological variability in ANC in order to provide scientific evidence for planning and management of local water resources.

During the past decades, climate conditions have been rapidly changed in ANC $[9,11]$, where precipitation significantly increased at a rate of $0.55 \mathrm{~mm} / \mathrm{a}$ [12], temperature rose at $0.34^{\circ} \mathrm{C} / 10$ a [10] during the period from 1993 to 2010, and, as a result, pan evaporation increased at $10.7 \mathrm{~mm} / \mathrm{a}^{2}$ [13]. The changing climate is likely to amplify the hydrological variability and affect the availability of water resources in this region. Glacier melt and snowmelt are important water sources in ANC. Many glaciers in western China have been observed to continuously retreat because of the increasing temperature. In the Tarim Basin, located in the southern part of the region, the proportion of glacial meltwater runoff increased from $41.5 \%$ in $1961-1990$ to $46.5 \%$ in $1991-2006$ [14]. Ding et al. [15] reported that $82.2 \%$ of glaciers in western China have retreated over the past 50 years and glacier areas decreased by $4.5 \%$ in the late 1950 s to the late 1990 s. As a result, hydrological conditions of the areas mainly supplied by glacier melt and snowmelt have been subjected to rapid changes.

Recently, some studies have examined TWSA in subregions of ANC. Yang and Chen [16] reported that TWSA exhibited a downward trend in the past years in the Tianshan Mountains of the central ANC region due to accelerating glacial ablation based on GRACE satellite and Global Land Data Assimilation System (GLDAS) model data. However, in the Tarim River Basin south to the Tianshan Mountains, TWSA was reported to increase because of the joint contributions of runoff and increased precipitation using the same approach [17]. This implies that hydrological variability in ANC may differ from one place to another and gives incentive to understand hydrological variabilities and their responses to climate change in a complete ANC as those subregions are in the same geographic aridity zone.

The main objective of this study is to examine hydrological variabilities of TWS and its major components in the entire ANC and three subregions with distinct climate characteristics on multiple time scales. Special aims include (i) quantifying the change rate of TWSA in the entire ANC and the three subregions during the past decade, (ii) examining the variabilities in TWS components on multiple time scales, and (iii) investigating potential factors affecting hydrological variabilities. These findings will be beneficial to sustainable water resource management and ecological protection in arid regions in the context of climate change.

\section{Data and Methods}

2.1. Study Area. The ANC is located at the center of the Eurasian continent far from oceans (Figure 1) and covers an area of approximately 2.15 million $\mathrm{km}^{2}$ bounded by longitude $73^{\circ}-108^{\circ} \mathrm{E}$ and latitude $34^{\circ}-50^{\circ} \mathrm{N}$. This region accounts for approximately $22 \%$ of China's territory, comprising Xinjiang Uygur Autonomous Region, the Hexi Corridor in Gansu Province, parts of Ningxia Hui Autonomous Region, and the western portion of the Helan Mountains in Inner Mongolia Autonomous Region. The region is surrounded by Kunlun Mountains, Qilian Mountains, and Altai Mountains. Those high mountains and the Tibetan Plateau (also known as High Asia) to the north effectively block moisture from the Indian Ocean from reaching this area. Meanwhile, Altai Mountains to the north prevent the transport of moisture from the Arctic Ocean. The region has a typical continental arid climate featuring strong westerly winds, large temperature fluctuations, scarce precipitation, and high potential ET. Annual precipitation in ANC is less than $200 \mathrm{~mm}$ [18] and the reference ET is in the range $1000 \sim 4500 \mathrm{~mm}$ [8].

The ANC has a vast territory of complex topography that includes mountains, plateaus, deserts, and basins [8]. The formation and dissipative zones are separated. Water is primarily supplied in mountainous areas and consumed in plain, oasis, and desert areas. Various types of rivers and lakes have been developed in this region (Figure 1). Most of them are seasonal bodies of water primarily supplied by ice and snowmelt from the mountains and precipitation [8].

\subsection{Data and Preprocessing}

2.2.1. GRACE Data. GRACE data are available from three different processing centers: Center for Space Research (CSR) at the University of Texas, Austin, GeoForschungsZentrum (GFZ) Potsdam, and Jet Propulsion Laboratory (JPL). The latest Level 2 Release 05 (RL05) gravity field products provided by CSR [19] were used in this study. These Level 2 data consist of a set of spherical harmonic coefficients with a degree and order of 96 . We truncated them to a degree and order of 90 due to serious noise issues at the high levels of degree and order. GRACE data do not provide degree $1\left(C_{10}, C_{11}\right.$, and $\left.S_{11}\right)$ coefficients, so these coefficients were replaced with the values estimated by Swenson et al. [20]. Likewise, the low-accuracy $C_{20}$ coefficients in GRACE data were replaced with estimates from Satellite Laser Ranging. Time-variable gravity models were obtained by removing the average of all monthly models from each monthly model between August 2002 and December 2013. A "destriping" algorithm [21] was used to remove the correlated errors and prevent "stripes" in the results. Then, a fan filter [22] with a radius of $350 \mathrm{~km}$ was applied to remove the remaining noise in the data. The final monthly TWSA was gridded to $0.1^{\circ}$ by $0.1^{\circ}$. Additionally, glacial isostatic adjustment effects were removed from the GRACE results because these effects can cause a secular trend in the gravity field not associated with the hydrological signals.

We compared the produced TWSA time series with three standard monthly gridded GRACE TWSA products from CSR, GFZ, and JPL, all based on RL05 spherical harmonics (Figure 2). The baseline periods were adjusted to a uniform period of 2002.08-2013.12 from the original 2004-2009 by subtracting the mean fields over the new 


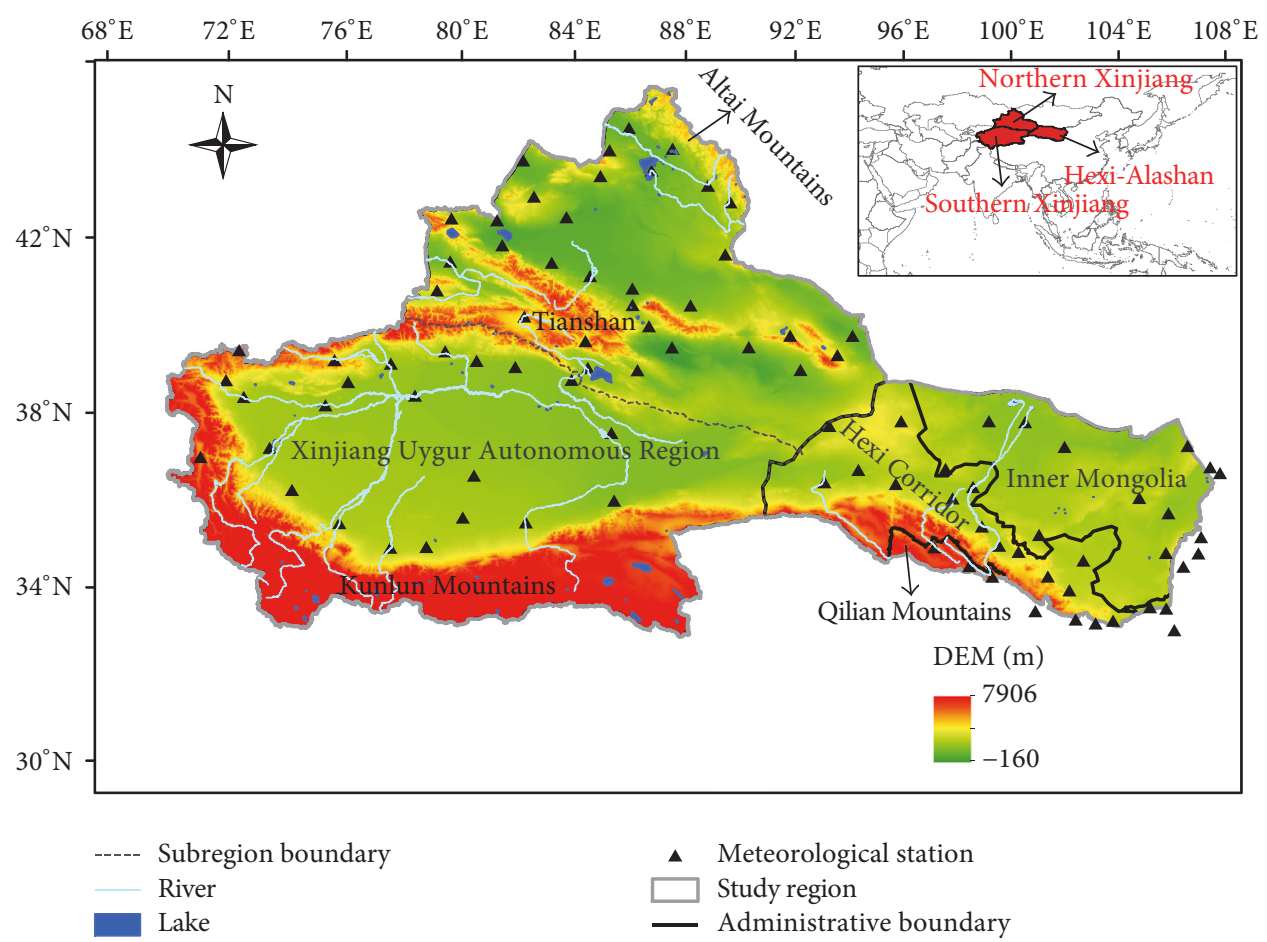

FIGURE 1: Location map showing the arid region of Northwest China (ANC) and its three subregions.

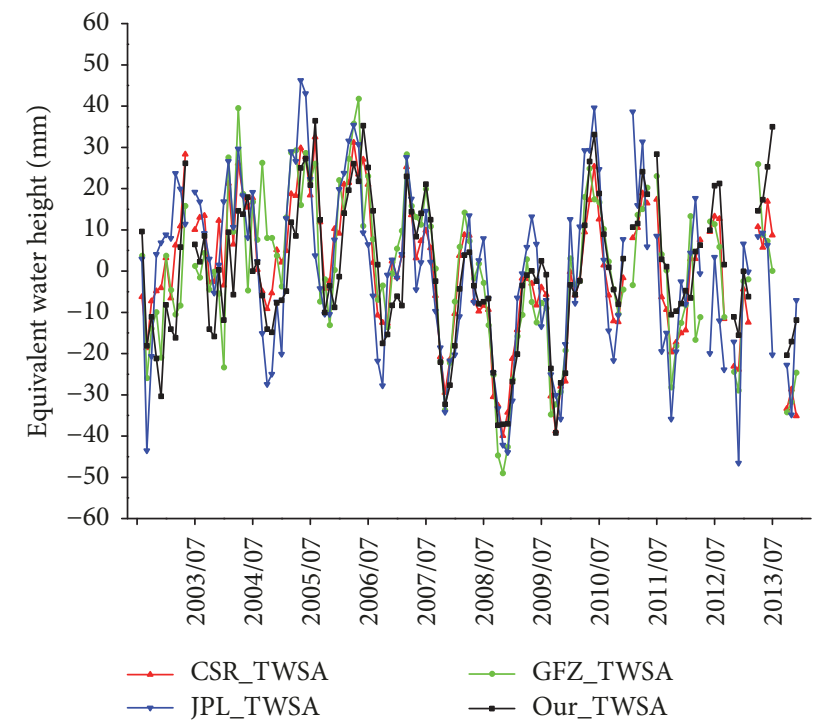

FIGURE 2: Comparison between TWSA time series produced in this study (Our_TWSA) and from three standard GRACE products (CSR, GFZ, and JPL).

period from the monthly TWSA fields. Figure 2 shows that all the four GRACE TWSA time series agree with each other quite well except in some months. For example, GFZ TWSA is opposite in trend to others near the end of 2004. The discrepancies among the four TWSA data points are an overall result of different gravity solutions used and the various processing approaches. We used a fan filter with a radius of $350 \mathrm{~km}$ recommended by Zhang et al. [22] to remove the noises in the data, while the standard GRACE products applied a $300 \mathrm{~km}$ Gaussian filter. The correlation coefficients between the produced TWSA and the three standard GRACE TWSA products are $0.87,0.80$, and 0.70 , respectively. While preserving a similar variation trend, the produced TWSA tends to fall within the envelope bounded by JPL and GFZ TWSA (Figure 2). Moreover, the produced TWSA data in this study, validated with the hydrological model, were shown to be accurate over our study area [23].

2.2.2. Soil Moisture Data. The gridded soil moisture data in ANC were obtained from GLDAS models outputs [24]. The average of three models (Noah, Mosaic, and VIC) was used as the best estimate. To estimate the errors in GRACE data induced by applying filters and truncating spherical harmonic coefficients, the monthly GLDAS soil moisture data were reprocessed using the same processes as employed for GRACE data. The soil moisture data were firstly expanded using spherical harmonic coefficients with a degree and order of 90 [25] and a fan filter with a $350 \mathrm{~km}$ radius was applied. After that, the spherical harmonic coefficients were converted to the final soil moisture dataset.

2.2.3. Snow Water Equivalent Data. The snow water equivalent (SWE) data were computed from snow depth data [26] which were derived from a variety of remote sensing sources, including Special Sensor Microwave Imager, Special Sensor Microwave Imager/Sounder, and Scanning Multichannel Microwave Radiometer datasets. Because this snow depth dataset considers the influences of vegetation, 
precipitation, wet snow, cold desert areas, and frozen ground, the spatial and temporal distributions of snow depth over China provided by this dataset were validated and shown to be more accurate than other global products over China. The same data have been used to study the response of streamflow to climate in the headwaters of the Yellow River Basin [27] and the seasonal and abrupt changes in the water levels of closed lakes on the Tibetan Plateau [28].

2.2.4. Meteorological Data. The climate data, including monthly (2002-2013) and annual (1961-2013) precipitation and temperature data, were collected from 76 meteorological stations located within the ANC. The gridded precipitation $P$ (mm) was computed using

$$
P=P_{0}\left[\frac{1+\chi\left(z-z_{0}\right)}{1-\chi\left(z-z_{0}\right)}\right],
$$

where $P_{0}$ is the interpolated station precipitation $(\mathrm{mm}), z_{0}$ is the interpolated station elevation surface ( $\mathrm{km}$ a.s.l.), $z$ is the gridded elevation ( $\mathrm{km}$ a.s.l.), and $\chi$ is the precipitationelevation adjustment factor $\left(\mathrm{km}^{-1}\right)$, which varies monthly. The adjustment factors were estimated by weighted leastsquares regression (see (2)) using observations at 76 meteorological stations:

$$
\frac{P_{1}-P_{2}}{P_{1}+P_{2}}=\chi\left(z_{1}-z_{2}\right)
$$

where $P_{n}$ and $Z_{n}(n=1$ or 2$)$ are precipitation and elevation at the pair stations, respectively.

The gridded temperature $T\left({ }^{\circ} \mathrm{C}\right)$ was obtained using (3) based on the lapse rate of air temperature $\Gamma\left({ }^{\circ} \mathrm{C} \cdot \mathrm{m}^{-1}\right)$ :

$$
T=T_{0}-\Gamma\left(z-z_{0}\right),
$$

where $T_{0}$ is the observed station temperature at station elevation $z_{0}$. The air temperature lapse rates vary by month and are provided by Kunkel [29].

\subsection{Methodology}

2.3.1. Dividing Subregions. The climate and topography in ANC are highly heterogeneous. The Xinjiang region is composed of Northern Xinjiang and Southern Xinjiang with the Tianshan Mountains between them as a natural geographical dividing line (Figure 1). The Helan Mountains to the east and the Qilian Mountains to the south enclose the Hexi Corridor and the Alashan Plateau. Given the distinct terrain, climate, and hydrological characteristics, the ANC can be divided into three subregions, that is, Northern Xinjiang, Southern Xinjiang, and the Hexi-Alashan Plateau, as marked in Figure 1.

Figure 3 shows the precipitation and air temperature variations in the entire ANC and its subregions in 1961-2013. Standard deviation and $p$ values were provided along the trend analysis. A smaller $p$ value indicates higher statistical significance. There are obvious increasing trends in annual precipitation and temperature. Spatially, the increase rate of precipitation was $0.28 \pm 0.19(p=0.14), 0.93 \pm 0.23(p<$ $0.01)$, and $0.71 \pm 0.20(p<0.01) \mathrm{mm} / \mathrm{a}$ in the Hexi-Alashan (Figure 3(b)), Northern Xinjiang (Figure 3(c)), and Southern Xinjiang (Figure 3(d)) subregions, respectively. The HexiAlashan region has the smallest increase rate of precipitation and Northern Xinjiang has the largest. The regional average of annual precipitation in 1961-2013 was approximately $85 \mathrm{~mm}$ in Southern Xinjiang, $177 \mathrm{~mm}$ in Northern Xinjiang, and $132 \mathrm{~mm}$ in Hexi-Alashan, respectively. Northern Xinjiang had the highest annual precipitation but the lowest air temperature $\left(\sim 6.1^{\circ} \mathrm{C}\right)$ among the three subregions. By contrast, Southern Xinjiang has less precipitation $(85 \mathrm{~mm})$ but a higher air temperature $\left(\sim 9.6^{\circ} \mathrm{C}\right)$ than Northern Xinjiang. Among the three subregions, temperature increase is the largest in Hexi-Alashan $\left(0.0352 \pm 0.0042^{\circ} \mathrm{C} / \mathrm{a}, p<0.01\right)$, followed by Northern Xinjiang $\left(0.0348 \pm 0.0057^{\circ} \mathrm{C} / \mathrm{a}, p<0.01\right)$ and Southern Xinjiang $\left(0.0257 \pm 0.0037^{\circ} \mathrm{C} / \mathrm{a}, p<0.01\right)$. In 1961-2013, Hexi-Alashan had the lowest rate of increase in precipitation and the highest rate of increase in temperature.

Potential ET is generally high in Southern Xinjiang $(2000-3000 \mathrm{~mm})$ and low in Northern Xinjiang $(1300-2300 \mathrm{~mm})$ [8]. Generally, potential evaporation in the study area is low in the west and high in the east, low in the mountains (drainage divides) and high in the lower areas, and low in the interiors of basins and high outwards [8].

2.3.2. Fitting Hydrological Signals Model. The derived hydrological signals generally consist of secular, periodic variations and the residuals. We used (4) to best fit the signals:

$$
\begin{aligned}
g(\varphi, \lambda, t)= & A+B t+\sum_{i=1}^{i=3} C_{i} \cos \left(\omega_{i} t\right)+D_{i} \sin \left(\omega_{i} t\right) \\
& +\varepsilon
\end{aligned}
$$

where $(\varphi, \lambda)$ is (colatitude, longitude), $\omega$ is the frequency ( $\omega_{i}=2 \pi / T_{i}$, where $T_{i}$ is the period), and $t$ is time. $A$ represents a constant and $B$ is a linear coefficient. The indices $i=1$ and 2 indicate annual and half-year periods, respectively. The 161-day S2 tide alias, which might be caused by an insufficient ocean tide correction, is denoted by the index $i=3$. $\varepsilon$ is the residual. A positive value of $B$ represents an increasing trend, while a negative $B$ value represents a decreasing trend.

Following this model, the anomaly signals in GRACE TWSA and precipitation could be obtained by removing the annual and semiannual cycles and tide alias information.

2.3.3. Uncertainty in GRACE TWSA. The uncertainty in GRACE TWSA can be categorized into (1) measurement error and (2) leakage error. The measurement error was calculated using Wahr et al.s method [30] and obtained by removing the constant, annual cycles, half-annual cycles, and 161-day S2 tide alias from the 128 monthly spherical harmonic coefficients after fitting with (4). The leakage error was estimated using Landerer and Swenson's method [31]. First, based on the raw unfiltered GLDAS soil moisture content 


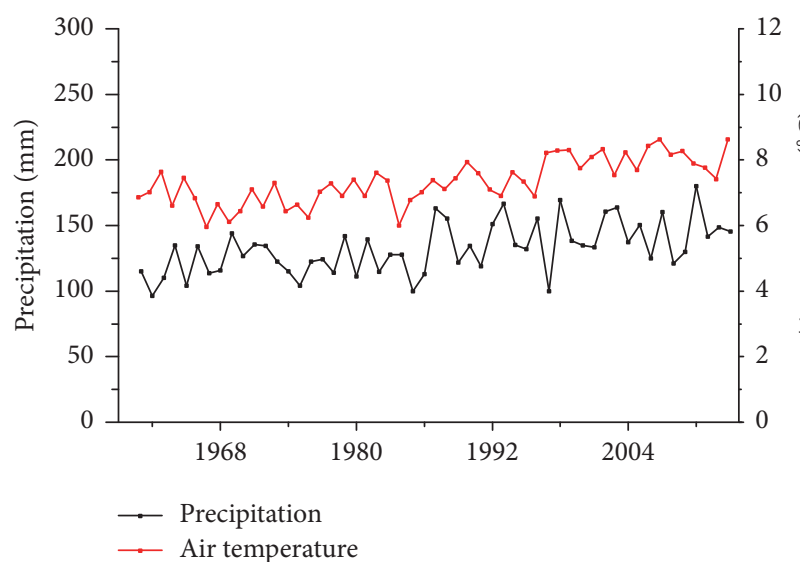

(a) Entire study region

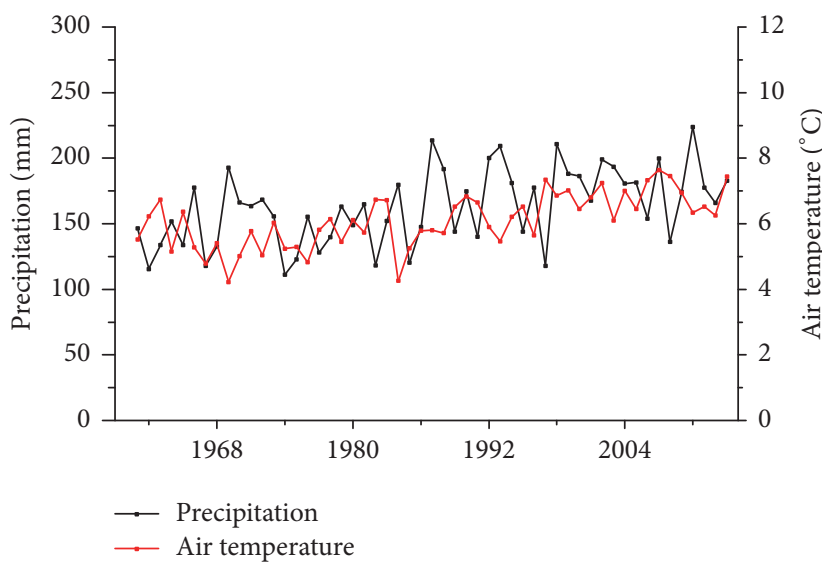

(c) Northern Xinjiang

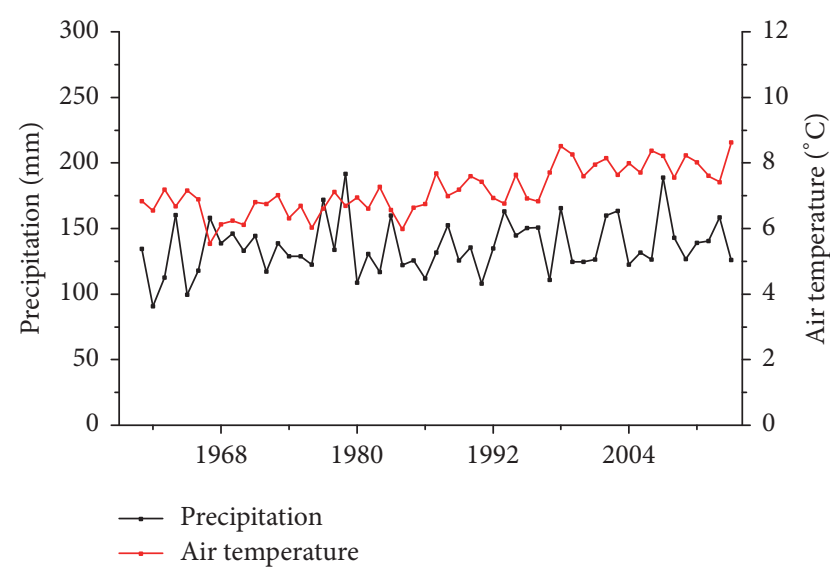

(b) Hexi-Alashan region



(d) Southern Xinjiang

FIGURE 3: Precipitation and air temperature variations in the entire ANC and its subregions in 1961-2013.

$\left(\mathrm{SM}_{r}\right)$ and the filtered soil moisture content $\left(\mathrm{SM}_{f}\right)$, a scale factor $k$ was calculated based on a least-squares regression in

$$
\Delta=\sum\left(\mathrm{SM}_{r}-k \mathrm{SM}_{f}\right)^{2} .
$$

Then, the leakage error was estimated using

$$
\varepsilon_{\text {leakage }}=\operatorname{RMS}\left(\mathrm{SM}_{r}-k \mathrm{SM}_{f}\right) \frac{\mathrm{RMS}_{\mathrm{GRACE}}}{\mathrm{RMS}_{\mathrm{SM}_{f}}},
$$

where RMS indicates the root mean square of the time series.

The amplitude of GRACE-derived TWS may be damped because of filtering and coefficient truncation. We applied a scaling factor $(k)$ of 1.12 , which was estimated using (5), to adjust the TWSA, as noted in many previous studies $[32,33]$.

2.3.4. Water Mass Balance Approach. The total TWS is a vertical integration of groundwater, soil moisture, snow, ice, surface water, and wet biomass. In a specific region, TWSA equates to the sum of the contributions of the different constituents, as expressed in (7), while neglecting the biomass component:

$$
\mathrm{TWSA}=\Delta \mathrm{SM}+\Delta \mathrm{GW}+\Delta \mathrm{SWE}+\Delta \mathrm{SW}
$$

where $\Delta \mathrm{SM}$ represents soil moisture anomaly, $\Delta \mathrm{GW}$ is groundwater storage anomalies in aquifers, $\triangle \mathrm{SWE}$ is SWE anomaly, and $\Delta \mathrm{SW}$ is the anomalies in total surface water, including water in lakes, reservoirs, and rivers.

Among these components, surface and ground water anomalies are difficult to measure. Soil moisture content can be estimated by models, and SWE can be determined via remote sensing methods. Therefore, in this study, we focused on investigating the relationships between TWSA and soil moisture and SWE anomalies.

2.3.5. Variability Analysis. Climate change due to global warming will significantly affect the water cycle in the arid region of northwest China [10]. In arid regions such as ANC, precipitation is the most important source of all forms of water storage. Air temperature changes can cause changes in ET and snow/ice/glacier melt and possible permafrost degradation and consequently affect the TWSA.

With the produced TWSA data, both temporal and spatial variabilities of hydrological variability in the entire ANC were examined. The variabilities in subregions were specially analyzed on different temporal scales (monthly, seasonal, and annual). The factors contributing to variations in TWSA and 


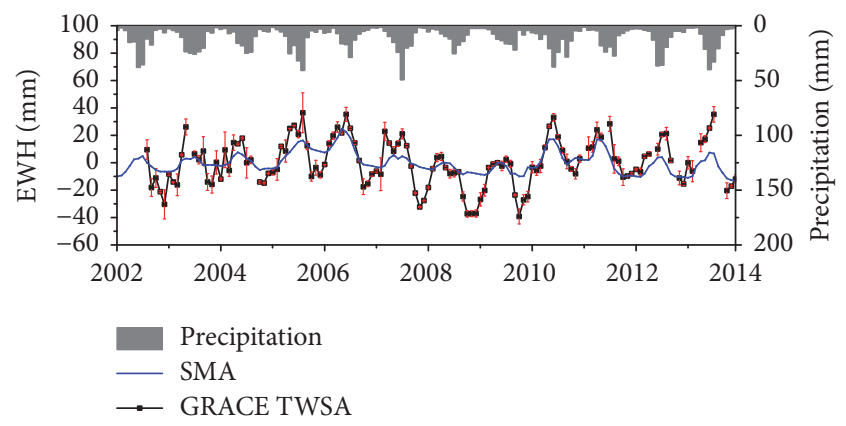

(a)

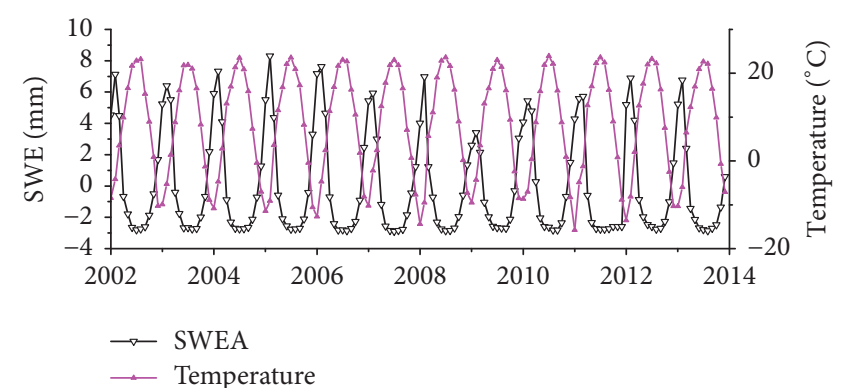

(b)

FIGURE 4: Regional averages of TWSA, soil moisture anomaly (SMA), snow water equivalent anomaly (SWEA), precipitation, and temperature in the entire ANC.

its components in the study period were specially investigated, particularly under the changing climate. Standard deviation and $p$ statistics were used to quantify possible errors and significance.

\section{Results and Discussion}

\subsection{Variability in the Entire Region}

3.1.1. Temporal Variability. Figure 4(a) presents regionaveraged GRACE-derived TWSA and soil moisture anomaly (SMA) represented as equivalent water height $(\mathrm{EWH})$ in August 2002 through December 2013, together with the variations of monthly precipitation. TWSA in the period exhibited strong seasonal variability with a slight increasing trend of $\sim 1.7 \mathrm{~mm} / \mathrm{a}$. The region-averaged SMA had a smaller variability than TWSA, with an oppositely decreasing trend $(-0.54 \mathrm{~mm} / \mathrm{a})$. TWSA and SMA agreed relatively well in seasonal fluctuation, with peaks appearing in/around July and valleys in/around November. However, in a finer time frame, annual TWSA and SMA kept increased from 2002 to 2006, dropped between 2007 and 2009, and were then restored after 2010. The SWE anomaly (SWEA) shown in Figure 4(b) also had obvious seasonal variations, with an overall decrease rate of $-0.1 \mathrm{~mm} / \mathrm{a}$. SWEA was remarkably lower in 2009 than in other years, while in the same year both TWSA and SMA were consistently low. Generally, SMA constituted a larger proportion of TWSA in ANC than SWEA, while SWEA cannot be neglected in the months when the snow starts to melt. Although we did not have direct groundwater storage and surface water storage data in this region, those storage amounts were estimated to rise throughout the study period by (7).

Figure 4(a) shows a high agreement in trend between TWSA and the precipitation variations. Throughout this period, precipitation was increasing at a rate of $0.12 \mathrm{~mm} / \mathrm{a}$, in the same upward trend as TWSA. As in the arid region, precipitation is the major source to TWS; a high positive correlation $(R=0.80)$ was found between TWSA and precipitation in ANC. By comparing the two time series, TWS was recharged during the rainy season (April through September) and depleted during the dry season (October through next March). In the consecutive years of 2008 and

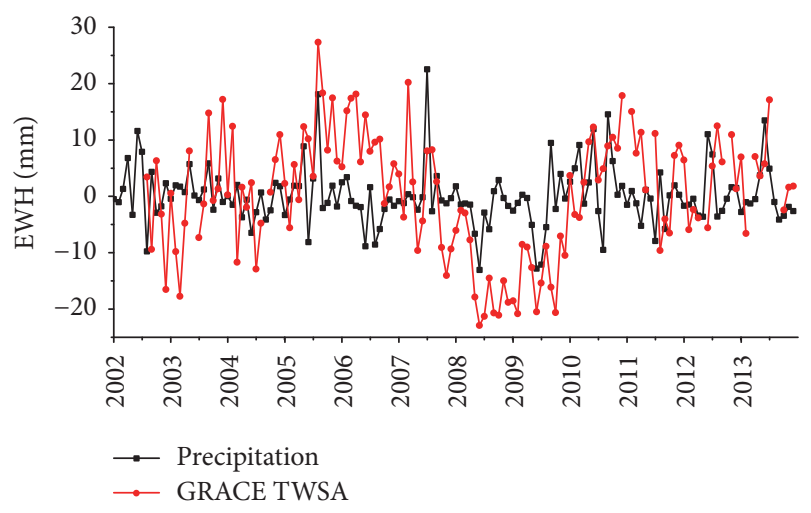

FIGURE 5: Best-fitted TWSA and precipitation anomaly in the entire ANC.

2009, TWS was severely depleted, reflecting the occurrence of severe drought disasters. Correspondingly, precipitation in the two years was obviously lower than in other years. Meanwhile, the temperatures in the winters of 2008 and 2009 were remarkably high, also resulting in loss in SWE and diminished TWS. The correlation between temperature and TWSA was 0.74 . As an overall result, a severe loss in TWS occurred in 2008 and 2009.

The correlation between climate factors and TWSA can be better represented after removal of annual and semiannual cycles and tide alias information using (4). Figure 5 displays the best-fitted GRACE TWSA and precipitation anomalies. It reveals a close connection between precipitation and TWSA. A noteworthy discrepancy can be found during the period of February 2008 through October 2009, in which a steady decrease in TWSA of approximately $22.2 \mathrm{~mm}$ occurred and the precipitation anomaly consistently decreased. But the range of TWSA was larger than that of precipitation anomaly. Given the fact that severe drought occurred in 2008-2009, it seems that TWSA is superior over precipitation in detecting wet and dry states and drought conditions.

The measurement error was estimated to be approximately $10.0 \mathrm{~mm}$ in RMS, as indicated by error bars in Figure 4(a). The leakage error was approximately $11.0 \mathrm{~mm}$ based on (6). Thus, the total error was approximately $14.9 \mathrm{~mm}$ by summing up both measurement and leakage errors. 


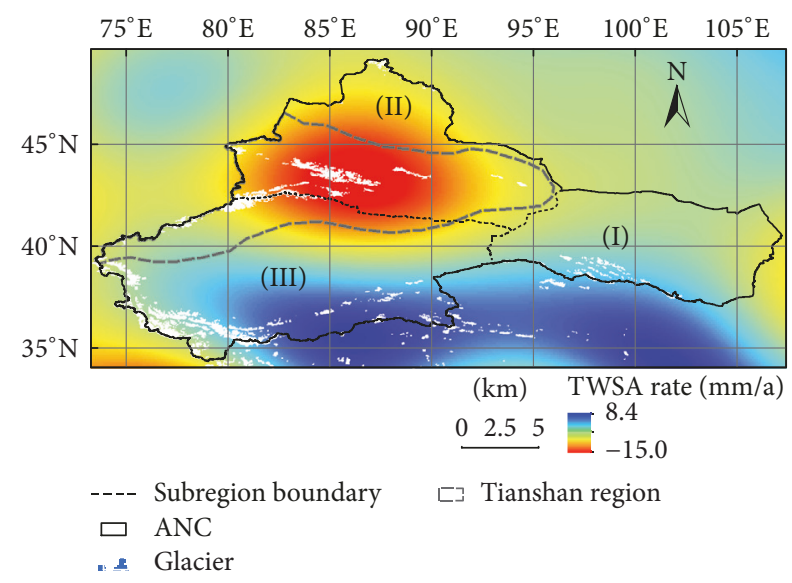

FIGURE 6: Spatial variability of GRACE TWSA trend in the entire ANC region and its three subregions: (I) Hexi-Alashan, (II) Northern Xinjiang, and (III) Southern Xinjiang.

3.1.2. Spatial Variability. The spatial variability of the TWSA trend (in mm/a) from August 2002 to December 2013 is shown in Figure 6. Large spatial variations existed over the entire ANC in terms of TWSA trend. The largest decrease, a rate of up to $\sim-15.0 \pm 1.2 \mathrm{~mm} / \mathrm{a}$ in EWH, occurred around the Tianshan region of Northern Xinjiang. By contrast, TWSA exhibited an obvious positive trend of $\sim 8.3 \pm 1.2 \mathrm{~mm} / \mathrm{a}$ in the southern ANC. Relatively stable TWSA trends were observed in the eastern ANC, that is, near the Hexi Corridor and Alashan Plateau. The variations in TWSA trend were much stronger in the western alpine region where massive glaciers and permafrost are extensively developed. Figure 6 reveals that the TWSA trend varies in space with general characteristics analogous to terrains in this region. Meanwhile, local climatic conditions and hydrological regimes alter the overall pattern to form local specials. For example, local hydrological conditions such as groundwater, soil moisture, snow/ice water, and surface water are likely to affect TWSA as an integrated variable. Thus, we further investigated the variations in TWSA trend on a finer subregion scale (Southern Xinjiang, Northern Xinjiang, and Hexi-Alashan).

Figure 7(a) presents the interannual variability in TWSA by subregion. The annual TWSA significantly declined in Northern Xinjiang at a rate of approximately $-3.64 \pm$ $1.17 \mathrm{~mm} / \mathrm{a}(p<0.05)$ in 2003-2013 whereas it increased in Hexi-Alashan and Southern Xinjiang. The increase rate was larger in Southern Xinjiang $(2.14 \pm 1.19 \mathrm{~mm} / \mathrm{a}, p=$ $0.10)$ than in Hexi-Alashan $(1.63 \pm 0.45 \mathrm{~mm} / \mathrm{a}, p<0.01)$, but statistically less significant. Both Southern Xinjiang and Northern Xinjiang subregions experienced critical water storage, leading to severe drought disasters, in 2008 to 2009, which was not present in Hexi-Alashan. The lowest TWSA of Northern Xinjiang occurred in 2009. Overall, multipleyear averaged TWSA was negative in Northern Xinjiang and positive in both Hexi-Alashan and Southern Xinjiang (Figure 7(b)). It was positive for the entire ANC, implying that the increased water storage in Hexi-Alashan and Southern Xinjiang exceeded the loss in Northern Xinjiang.
3.2. Intra-Annual Variability in Subregions. The intra-annual hydrological variations in TWS, soil moisture, SWE, and precipitation averaged over the study period in the three subregions are presented in Figure 8. TWS in Hexi-Alashan, Northern Xinjiang, and Southern Xinjiang started to surpass the average (ascended across zero of EWH) in March, February, and March, respectively, and descended across zero of EWH in September, August, and August, respectively. Rainfall was concentrated between May and September over the entire ANC, in which TWS increased rapidly in response in each region.

Meltwater from glacier and snow/ice are an important extra source, particularly in pre-rainy season months. Almost half of the total glaciated areas in China are located in Northwest China [8] and glacier meltwater is estimated to account for approximately $22 \%$ of the total annual flow in ANC [34]. The seasonal snowfall in vast mountain areas is "stockpiled" on the surface in winter and melts away in spring due to rising temperature. The climate warming in ANC accelerates the melting of alpine glaciers [35], snow, and permafrost [36], which would exert important effects on hydrological variabilities. Beginning in early spring, meltwater supplies water storage deficit. In the way flowing down, it evaporates. In the downslope areas with intense water use or groundwater overexploitation, the increased portion of water is used up. This way, the masses are spatially redistributed within and across subregions.

TWSA was the highest in June and July in Hexi-Alashan on the east and in Southern Xinjiang on the south $(\sim 12.2$ and $26.4 \mathrm{~mm}$, resp.) and the lowest in October $(\sim-8.8$ and $-24.2 \mathrm{~mm}$, resp.). In both regions, TWSA reached the maximum at approximately the same time as precipitation (Figures $8(\mathrm{a})$ and $8(\mathrm{c})$ ). However, it is different in Northern Xinjiang to the north of ANC. The largest TWSA occurred in May $(\sim 16.7 \mathrm{~mm})$ and the lowest occurred in November $(-18.9 \mathrm{~mm})$. It did not coincide with precipitation, whose maximum was in July (Figure 8(b)). As Northern Xinjiang is the most developed area in Xinjiang, the intense human activities together with the contributions of glacier/snow meltwater and high potential ET may explain this divergence. The minimum TWSA was found around October or November in all subregions, the months with little precipitation and high water demands for winter irrigation. Among the three, Southern Xinjiang had the largest monthly TWSA, lowest total rainfall, and highest temperature. TWSA in Southern Xinjiang was well coincident with precipitation throughout the year except in spring. In spring, the neighboring High Asia recharged this region with glacier meltwater till May (Figure $8(\mathrm{c})$ ). This demonstrates the role of glacier meltwater in the TWS water cycle.

On a seasonal scale, the three subregions exhibited much similar variability, with increases in spring and summer and decreases in autumn and winter. TWSA increased more in summer than in spring in Hexi-Alashan and Southern Xinjiang and was opposite in Northern Xinjiang. TWSA was the least in autumn and winter in Hexi-Alashan. The seasonality of TWS was most prominent in Southern Xinjiang and least prominent in Hexi-Alashan. 


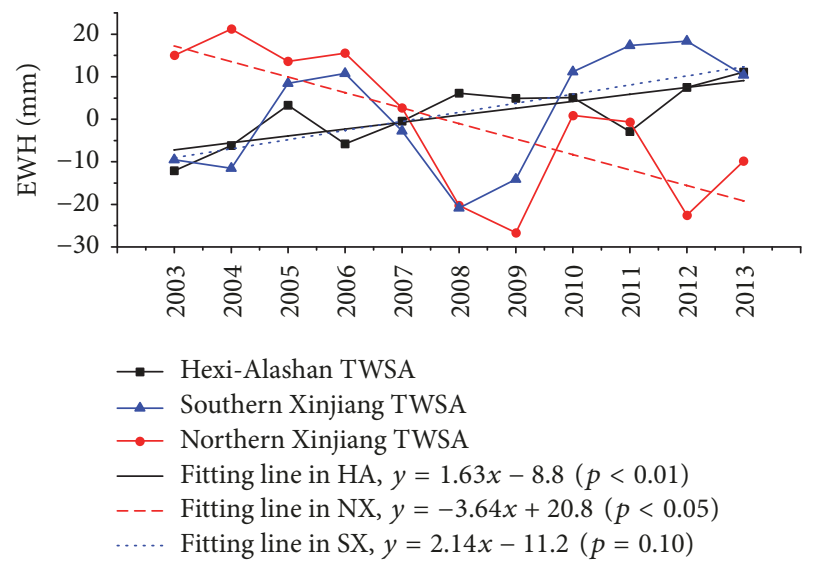

(a)

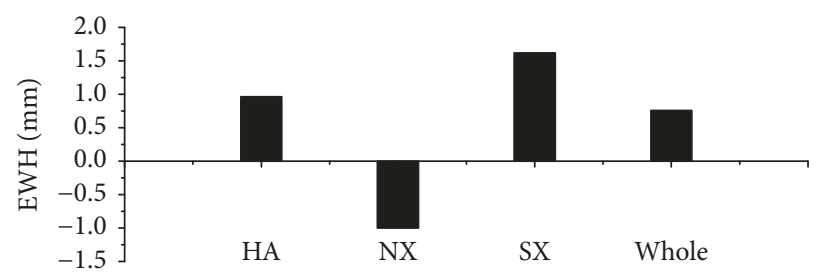

(b)

FIGURE 7: Interannual variability of TWSA in the ANC subregions.

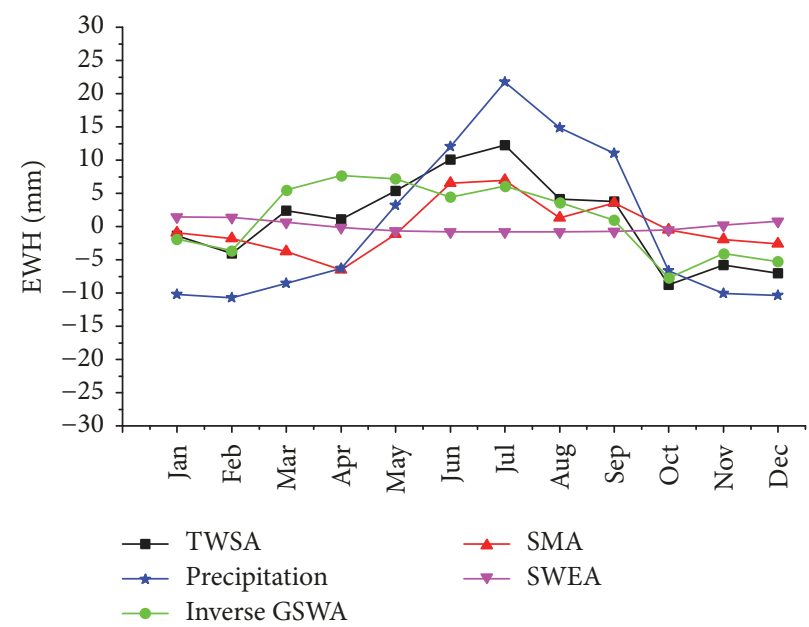

(a) Hexi-Alashan

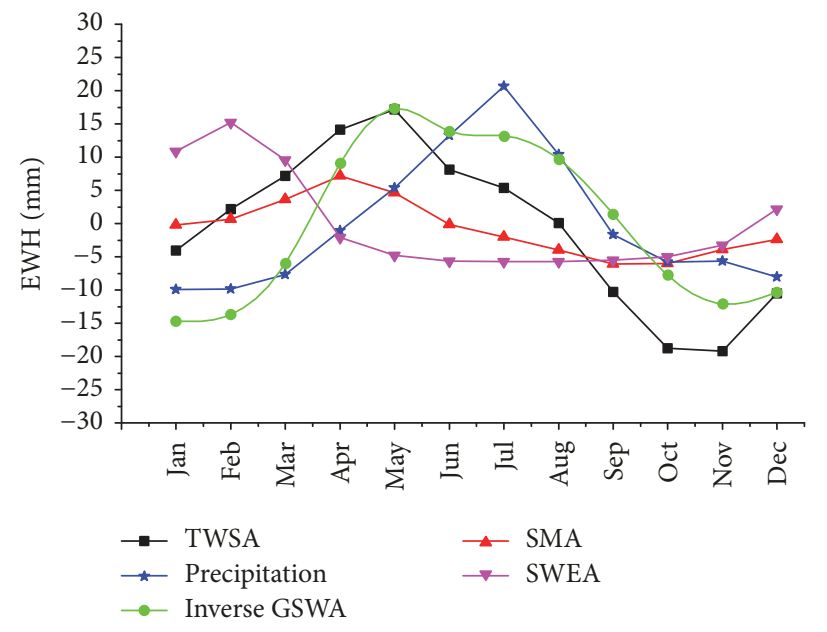

(b) Northern Xinjiang

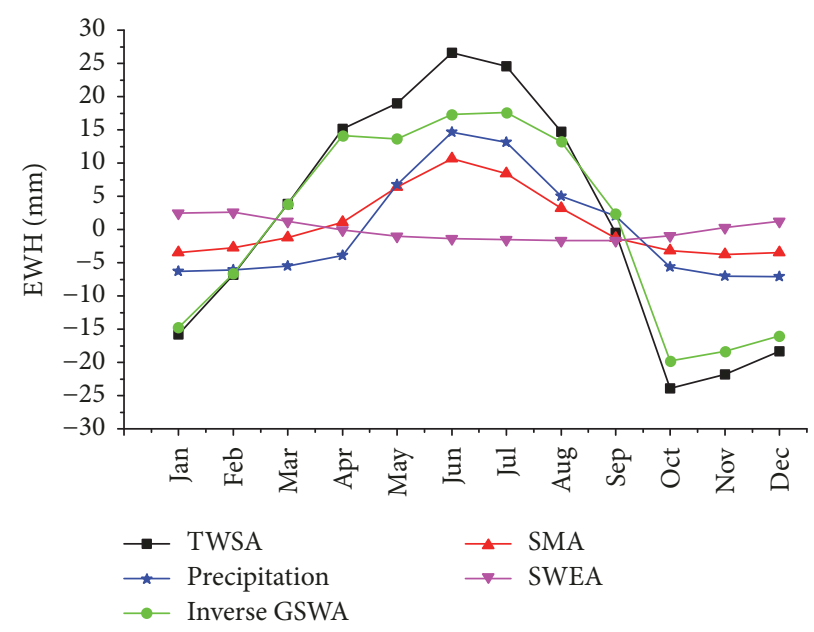

(c) Southern Xinjiang

FIGURE 8: Multiple-year averaged monthly variations of TWSA and its components (SMA, SWEA, and inverse GSWA) as well as precipitation in the three subregions. 
SMA displayed similar monthly variability to TWSA but with overall smaller amplitude. SMA in Southern Xinjiang did not fluctuate much and had a relatively small amplitude because of the extreme aridity in Southern Xinjiang. The largest desert in China, the Taklimakan Desert, is located there. The desert soils have a low capability for water storage. The soil moisture in Hexi-Alashan and Southern Xinjiang surpassed the average in spring and summer and dropped below the average in autumn and winter. Unlike TWSA, the seasonal change patterns of SMA differed by subregion. Maximum soil moisture anomaly $(\sim 5.2 \mathrm{~mm})$ in Northern Xinjiang occurred in spring when soil moisture was primarily fed by glacier ablation and snow/ice thawing, whereas maximum TWSA occurred in summer when soil moisture began to decrease.

SWEA generally surpassed the average in winter and spring and dropped in summer and fall but its characteristics varied by subregion. The seasonal oscillation was the smallest in Hexi-Alashan and accounted for a small portion of TWSA. By contrast, it was large in Northern Xinjiang. SWEA in February was approximately $15 \mathrm{~mm}$ in Northern Xinjiang, five times higher than that in Southern Xinjiang in the same month. This indicates that SWEA constituted an important portion of TWSA in Northern Xinjiang, especially in winter.

Groundwater and surface water anomalies (GSWA) were inversely determined by (7). GSWA increased in spring (contributed by glacier and snowmelt) and summer (contributed by rain) in all subregions. GSWA was the greatest in spring in Hexi-Alashan. There is a big population along the "Hexi Corridor" in this region, consuming a great quantity of water through agricultural irrigation, urban and industrial uses, and so on. Although the amount of precipitation is large in summer, the losses in summer are also large owing to the large amount of water demands and high potential ET. The same situation exists in Northern Xinjiang. As a result, less GSWA was observed in summer than in spring in both Hexi-Alashan and Northern Xinjiang. In Northern Xinjiang, GSWA was the highest in May when TWSA was also the highest. High GSWA there in July was mainly caused by precipitation. In Southern Xinjiang, the correlation between TWSA and GSWA was as high as 0.99 because Southern Xinjiang has much fewer human activities than the other regions.

3.3. Impacts of Climatic Factors. Over the past 50 years, both precipitation and temperature presented an increasing trend in ANC and its three subregions (Figure 3). As discerned from Figure 6, the region-averaged TWSA in Hexi-Alashan was in a state of gain during the study period (Figures 7 and 9 (a)), with a rate of $0.15 \pm 0.03 \mathrm{~mm} /$ month. Precipitation and temperature were also increasing in that period at a rate of approximately $0.007 \mathrm{~mm} / \mathrm{month}$ and $0.006^{\circ} \mathrm{C} / \mathrm{month}$, respectively. Precipitation and air temperature are two important factors that affect regional TWSA. The increase in air temperature leads not only to high evaporation, which would consequently cause TWS loss, but also to glacier ablation in high mountains and permafrost degradation, by which solid water migrates to another region. The net gain between the increasing precipitation and the losses of ET
TABLE 1: Three stages detected by TWSA in Northern Xinjiang.

\begin{tabular}{lccc}
\hline Period & TWSA $(\mathrm{mm})$ & $\begin{array}{c}\text { Precipitation } \\
(\mathrm{mm})\end{array}$ & $\begin{array}{c}\text { Temperature } \\
\left({ }^{\circ} \mathrm{C}\right)\end{array}$ \\
\hline $2002-2007$ & 13.43 & 16.7 & 6.8 \\
$2008-2009$ & -14.76 & 14.0 & 7.3 \\
$2010-2013$ & -7.55 & 16.7 & 6.6 \\
\hline
\end{tabular}

and human activity-induced water consumption explains the overall increase in TWS in Hexi-Alashan.

The Qilian Mountains supply water resources to the Hexi-Alashan region. The glaciers in this region are about $811.2 \mathrm{~km}^{3}$ in volume [37]. The annual average streamflow from the Qilian Mountains is about $71 \mathrm{~km}^{3}$, which feeds about $7800 \mathrm{~km}^{2}$ of farmland and more than 5.5 million people [37]. Observations show declining streamflow from the Qilian Mountains ( $-6.7 \mathrm{~mm} / \mathrm{a}$ ) during 2003-2010 [37]. While there is accelerating glacial melting in the Qilian Mountains due to temperature increase [38], the mountainous areas tend to hold more water storage considering the overall increased precipitation and diminished discharge. The final result is that an increase in TWSA occurred in these areas (Figure 6). In addition, given that $50 \%$ of the area of the Qilian Mountains is underlain by permafrost, the temperature increase will thicken the active layer of permafrost and more liquid water flows downslope. The processes are complex and make the mass spatially redistributed. The overall results can be observed to some extent by the expanding lake areas scattered across the Hexi-Alashan region in 2000 through 2010 in response to changing climate [39]. Therefore, TWSA in Hexi-Alashan is closely controlled by climate factors such as precipitation, temperature, and evaporation, together with water consumption by human activities such as irrigation in oases. Glacier ablation and permafrost degradation in response to warming climate that occurred in mountainous areas are likely to affect the spatial pattern of TWSA in this region.

The time series of TWSA in Northern Xinjiang can be divided into three stages (Figure 9(b)). TWSA, precipitation, and temperature in the three stages are listed in Table 1 . The first stage is from January 2002 to December 2007, in which TWSA was high $(13.43 \mathrm{~mm})$ and precipitation $(16.7 \mathrm{~mm})$ and temperature $\left(6.8^{\circ} \mathrm{C}\right)$ were at average levels. TWSA abruptly dropped to $-14.76 \mathrm{~mm}$ in the second stage (January 2008 to December 2009). TWSA began to be restored in the third stage (January 2010 to December 2013), in which the mean monthly TWSA was $-7.55 \mathrm{~mm}$. Although TWSA remained in deficit, the climate conditions returned to the level in the first stage. The first stage is the wettest period, with a large amount of TWS caused by abundant precipitation and low temperature. The second stage is the driest period, with considerable TWS loss. This stage has smaller precipitation and higher temperature compared to the first stage. The notable loss of TWS is usually linked to drought disasters as discussed in previous sections and reported in a previous study [23]. After that, precipitation increased and temperature dropped in the following third stage, and drought conditions were 

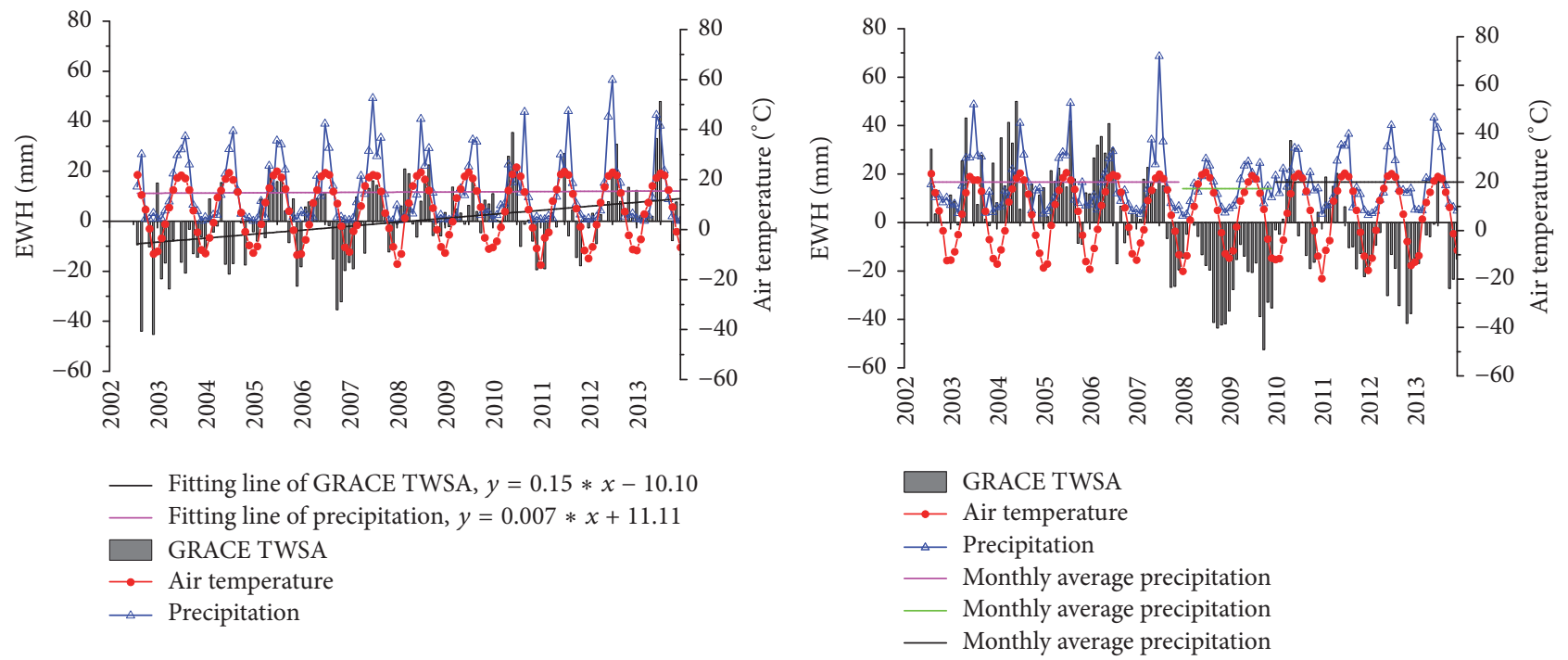

(a)

(b)

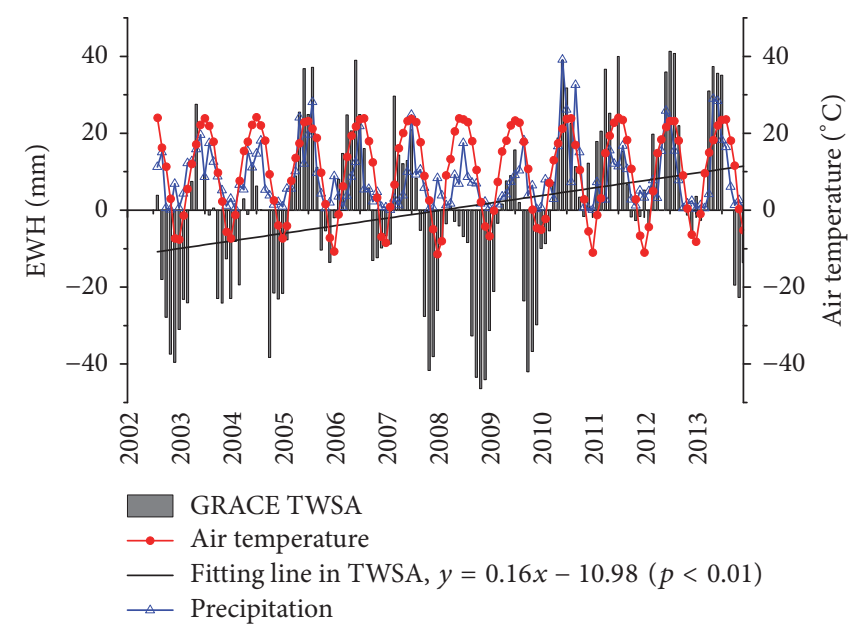

(c)

FIGURE 9: Variabilities and trends of GRACE TWSA and changing climatic conditions in the three subregions: (a) Hexi-Alashan, (b) Northern Xinjiang, and (c) Southern Xinjiang.

ameliorated as evidenced by the restored TWSA, which was, however, still below the mean over the entire period. The responses of TWSA in various stages show that TWS in Northern Xinjiang is highly controlled by precipitation and temperature.

Precipitation in Northern Xinjiang was declining at an average rate of $-1.0 \mathrm{~mm} / \mathrm{a}$ from January 2002 to December 2013. Apart from the changes in precipitation, glacier meltwater loss was an extra important factor leading to the overall decreased TWSA in Northern Xinjiang. The amount of glacier melt is highly related to rising temperature. Previous studies in the Tianshan Mountains and the adjacent areas reported a decrease rate of $-0.48 \mathrm{~mm} / \mathrm{month}$ in TWSA from January 2003 to December 2010 [40] and $-4.2 \pm 1.2 \mathrm{~mm} / \mathrm{a}$ over a longer period from January 2003 to March 2013 [16]. Our results agree well with those results, and we found a similar decreasing trend of TWS in the Tianshan Mountains in recent years. Matsuo and Heki [41] attributed the loss to the increase in glacial melting in response to climatic warming. The melted glacier water will result in more surface and groundwater draining to downslope areas and positively affect the downslope TWSA. Moreover, increases in human activities and economic development in middle reach areas have led to dramatic increases in water consumption [18]. Therefore, anthropogenic activities have offset the increased runoff by glacier meltwater and aggravated the TWS loss $[16,40]$. Overall, the reduction of TWS in Northern Xinjiang was impacted by decreasing precipitation, increasing glacier ablation, and intensified human activities.

The Southern Xinjiang-averaged TWSA exhibited strong seasonality (Figure 9(c)) with an increasing trend of $0.16 \pm$ $0.05 \mathrm{~mm} / \mathrm{month}$. TWSA was closely related to precipitation variations as similar seasonality was also observed in precipitation. For example, in the period of 2008-2009, both 
precipitation and TWSA were extremely low. This implies that TWSA was dominated by varying precipitation, which was also found in a previous study [42]. Nevertheless, the connection between the TWSA and increasing temperature was rather complex. Despite rising temperature, the annual potential ET was observed to drop at a rate of $-2.99 \mathrm{~mm} / \mathrm{a}$ $\left(R^{2}=0.41\right)$ at the Alar station in Southern Xinjiang during 1960-2015 [43]. Except for rainfall, glacial and snowfall melt from the Tianshan and Kunlun Mountains are important water sources for Southern Xinjiang [44]. They increased in response to rising temperatures in the Tarim Basin of Southern Xinjiang according to a previous study [42]. The contributions of glacier runoff account for as much as $60 \%$ of inflows to the Tarim Basin [45]. Wang et al. [46] observed increased runoff in most rivers on the south slope of Tianshan Mountains [19, 47]. Glacier meltwater diminishes in the way downward the plains and oases due to evapotranspiration from surface flow. There are many lakes in Southern Xinjiang, which are mainly supplied by glaciers and snow meltwater. Most of them were reported to have rising water levels during 2003-2009 [48], showing increased TWS in those areas. In addition, groundwater in the Tarim Basin is recharged through seepage when surface runoff moves downslope [17]. Yi and Sun [19] applied the GRACE RL05 models to a large region covering part of ANC and the Tibetan Plateau and observed strong positive signals there. In other words, it is likely that the adjacent Tibetan Plateau to the south may contribute more water supply to Southern Xinjiang. By putting those variables together, one can infer that the increase in TWS in Southern Xinjiang in the study period was potentially related to increasing precipitation in summer, decreasing potential ET, and contributions of glacier and snowmelt from the neighboring Tibetan Plateau.

\section{Conclusions}

This study investigated the spatiotemporal characteristics of hydrological variability in the arid region of Northwest China from August 2002 to December 2013 using GRACE-derived TWSA, GLDAS soil moisture output, and remote sensed snow water data.

In the study region, TWSA has increased at a rate of $1.7 \mathrm{~mm} / \mathrm{a}$ over the past decade, which mimicked the increasing trend of precipitation $(0.12 \mathrm{~mm} / \mathrm{a})$. TWSA in Northern Xinjiang, Southern Xinjiang, and Hexi-Alashan varied at a rate of $-3.64 \pm 1.17 \mathrm{~mm} / \mathrm{a}(p<0.05), 2.14 \pm$ $1.19 \mathrm{~mm} / \mathrm{a}(p=0.10)$, and $1.63 \pm 0.45 \mathrm{~mm} / \mathrm{a}(p<0.01)$, respectively. The decrease of TWSA in Northern Xinjiang was related to reduced precipitation, increased temperature, more glacial meltwater draining away from the Tianshan Mountain, and increased human activities consuming more water resources. Increases in precipitation and glacial melt in surrounding mountains and decreases in potential ET led to the increase in TWSA in Southern Xinjiang. The increased TWS in Hexi-Alashan was the tradeoff result of slightly increased precipitation and high rising temperature together with human activities. Increased glacier meltwater and permafrost degradation in response to climate warming may also influence the regional TWS balance.
TWSA and soil moisture anomaly exhibited strong seasonality across the ANC. TWS and soil moisture were recharged in rainy months (May-September) and depleted in dry months (October-April). Regionally, the soil moisture, groundwater, and surface water accounted for the major proportion of TWSA in Southern Xinjiang and Hexi-Alashan, while all the components contributed to the same extent to TWSA in Northern Xinjiang. The largest TWSA and smallest soil moisture anomaly were observed in Southern Xinjiang and the smallest TWSA was observed in Hexi-Alashan. In the case of identifying drought in 2008-2009 in the study area, TWSA is found to be superior over precipitation in detecting wet and dry states and drought conditions.

The method proposed takes advantage of remote sensing data and model outputs. It is able to depict a complete picture of spatiotemporal characteristics of hydrological variability in arid regions without the need for field observations and can be applied to other large arid areas around the world.

\section{Conflicts of Interest}

The authors declare no conflicts of interest regarding the publication of this paper.

\section{Acknowledgments}

This study was financially supported by the National Key R\&D Program of China (no. 2017YFA0603603), the National Natural Science Foundation of China (nos. 41701503 and 41471059), Scientific Research Start-Up Funding of the Program Supporting Special Talent Zone (Henan University), and Scientific Promotion Funding of the Prioritized Academic Discipline (Geography, Henan University). The authors would like to thank the Center for Space Research of the University of Texas at Austin for providing GRACE data. They are also grateful to Professor Matthew Rodell from NASA for the helpful and constructive comments that greatly contributed to improving the quality of the paper.

\section{References}

[1] J. Feng, D. Yan, C. Li, F. Yu, and C. Zhang, "Assessing the impact of climatic factors on potential evapotranspiration in droughts in north china," Quaternary International, vol. 336, pp. 6-12, 2014.

[2] N. Thevs, H. Peng, A. Rozi, S. Zerbe, and N. Abdusalih, "Water allocation and water consumption of irrigated agriculture and natural vegetation in the Aksu-Tarim river basin, Xinjiang, China," Journal of Arid Environments, vol. 112, pp. 87-97, 2015.

[3] R. S. J. Sparks and C. J. Hawkesworth, "Remote sensing of terrestrial water storage, soil moisture and surface waters, geophysical monograph," Geophysical Monograph, vol. 150, pp. 197-207, 2004.

[4] Y. Chen, Z. Li, W. Li, H. Deng, and Y. Shen, "Water and ecological security: dealing with hydroclimatic challenges at the heart of China's Silk Road," Environmental Earth Sciences, vol. 75, no. 10, article no. 881, 2016.

[5] L. Xavier, M. Becker, A. Cazenave, L. Longuevergne, W. Llovel, and O. C. R. Filho, "Interannual variability in water storage 
over 2003-2008 in the Amazon Basin from GRACE space gravimetry, in situ river level and precipitation data," Remote Sensing of Environment, vol. 114, no. 8, pp. 1629-1637, 2010.

[6] M. Rodell and J. S. Famiglietti, "An analysis of terrestrial water storage variations in Illinois with implications for the Gravity Recovery and Climate Experiment (GRACE)," Water Resources Research, vol. 37, no. 5, pp. 1327-1339, 2001.

[7] G. Strassberg, B. R. Scanlon, and M. Rodell, "Comparison of seasonal terrestrial water storage variations from GRACE with groundwater-level measurements from the High Plains Aquifer (USA)," Geophysical Research Letters, vol. 34, no. 14, Article ID L14402, 2007.

[8] Y. Chen, "Water resources research in northwest China," Water Resources Research in Northwest China, vol. 9789401780179, pp. 1-444, 2014.

[9] Y. N. Chen, Q. Yang, Y. Luo, Y. J. Shen, X. L. Pan et al., "Ponder on the issues of water resources in the arid region of northwest China," Arid Land Geography, vol. 35, no. 1, pp. 1-9, 2012.

[10] Y. Chen, Z. Li, Y. Fan, H. Wang, and H. Deng, "Progress and prospects of climate change impacts on hydrology in the arid region of northwest China," Environmental Research, vol. 139, pp. 11-19, 2015.

[11] Y. H. Ding, G. Y. Ren, Z. C. Zhao et al., "Detection, causes and projection of climate change over China: an overview of recent progress," Advances in Atmospheric Sciences, vol. 24, no. 6, pp. 954-971, 2007.

[12] P. Yang, J. Xia, Y. Zhang, and S. Hong, "Temporal and spatial variations of precipitation in Northwest China during 1960-2013," Atmospheric Research, vol. 183, pp. 283-295, 2017.

[13] Z. Li, Y. Chen, Y. Shen, Y. Liu, and S. Zhang, "Analysis of changing pan evaporation in the arid region of Northwest China," Water Resources Research, vol. 49, no. 4, pp. 2205-2212, 2013.

[14] X. Gao, B. S. Ye, S. Q. Zhang, C. J. Qiao, and X. W. Zhang, "Glacier runoff variation and its influence on river runoff during 1961-2006 in the Tarim River Basin, China," Science China Earth Sciences, vol. 53, no. 6, pp. 880-891, 2010.

[15] Y. J. Ding, S. Y. Liu, J. Li, and D. H. Shangguan, “The retreat of glaciers in response to recent climate warming in western China," Annals of Glaciology, vol. 43, pp. 97-105, 2006.

[16] P. Yang and Y. Chen, "An analysis of terrestrial water storage variations from GRACE and GLDAS: The Tianshan Mountains and its adjacent areas, central Asia," Quaternary International, vol. 358, pp. 106-112, 2015.

[17] T. Yang, C. Wang, Y. Chen, X. Chen, and Z. Yu, "Climate change and water storage variability over an arid endorheic region," Journal of Hydrology, vol. 529, no. 1, pp. 330-339, 2015.

[18] H. Wang, Y. Chen, S. Xun, D. Lai, Y. Fan, and Z. Li, "Changes in daily climate extremes in the arid area of northwestern China," Theoretical and Applied Climatology, vol. 112, no. 1-2, pp. 15-28, 2013.

[19] S. Yi and W. Sun, "Evaluation of glacier changes in highmountain Asia based on 10 year GRACE RL05 models," Journal of Geophysical Research: Solid Earth, vol. 119, no. 3, pp. 25042517, 2014.

[20] S. C. Swenson, D. P. Chambers, and J. Wahr, "Estimating geocenter variations from a combination of GRACE and ocean model output," Journal of Geophysical Research: Solid Earth, vol. 113, no. 8, Article ID B08410, 2008.

[21] S. C. Swenson and J. Wahr, "Post-processing removal of correlated errors in GRACE data," Geophysical Research Letters, vol. 33, no. 8, Article ID L08402, 2006.
[22] Z.-Z. Zhang, B. F. Chao, Y. Lu, and H.-T. Hsu, "An effective filtering for GRACE time-variable gravity: Fan filter," Geophysical Research Letters, vol. 36, no. 17, Article ID L17311, 2009.

[23] Y. Cao, Z. Nan, and G. Cheng, "GRACE gravity satellite observations of terrestrial water storage changes for drought characterization in the arid land of northwestern China," Remote Sensing, vol. 7, no. 1, pp. 1021-1047, 2015.

[24] M. Rodell, P. R. Houser, U. Jambor et al., "The global land data assimilation system," Bulletin of the American Meteorological Society, vol. 85, no. 3, pp. 381-394, 2004.

[25] H. S. Wang, P. Wu, and Z. Y. Wang, "An approach for spherical harmonic analysis of non-smooth data," Computers \& Geosciences, vol. 32, no. 10, pp. 1654-1668, 2006.

[26] T. Che, X. Li, R. Jin, R. Armstrong, and T. Zhang, "Snow depth derived from passive microwave remote-sensing data in China," Annals of Glaciology, vol. 49, pp. 145-154, 2008.

[27] H. Zheng, L. Zhang, R. Zhu, C. Liu, Y. Sato, and Y. Fukushima, "Responses of streamflow to climate and land surface change in the headwaters of the Yellow River Basin," Water Resources Research, vol. 45, no. 7, Article ID W00A19, 2009.

[28] C. Song, B. Huang, L. Ke, and K. S. Richards, "Seasonal and abrupt changes in the water level of closed lakes on the Tibetan Plateau and implications for climate impacts," Journal of Hydrology, vol. 514, pp. 131-144, 2014.

[29] K. E. Kunkel, "Simple Procedures for Extrapolation of Humidity Variables in the Mountainous Western United States," Journal of Climate, vol. 2, no. 7, pp. 656-670.

[30] J. Wahr, S. Swenson, and I. Velicogna, "Accuracy of GRACE mass estimates," Geophysical Research Letters, vol. 33, no. 6, Article ID L06401, 2006.

[31] F. W. Landerer and S. C. Swenson, "Accuracy of scaled GRACE terrestrial water storage estimates," Water Resources Research, vol. 48, no. 4, 2012.

[32] J. S. Famiglietti, M. Lo, S. L. Ho et al., "Satellites measure recent rates of groundwater depletion in California's Central Valley," Geophysical Research Letters, vol. 38, no. 3, Article ID L03403, 2011.

[33] W. Feng, M. Zhong, J.-M. Lemoine, R. Biancale, H.-T. Hsu, and J. Xia, "Evaluation of groundwater depletion in North China using the Gravity Recovery and Climate Experiment (GRACE) data and ground-based measurements," Water Resources Research, vol. 49, no. 4, pp. 2110-2118, 2013.

[34] X. Chen, Physical Geography of Arid Land in China, Science Press, Beijing, China, 2010.

[35] M. Dyurgerov, "Mountain and subpolar glaciers show an increase in sensitivity to climate warming and intensification of the water cycle," Journal of Hydrology, vol. 282, no. 1-4, pp. 164-176, 2003.

[36] J. Bockheim, G. Vieira, M. Ramos et al., "Climate warming and permafrost dynamics in the Antarctic Peninsula region," Global and Planetary Change, vol. 100, pp. 215-223, 2013.

[37] M. Xu, "Study on water storage change and its consideration in water balance in the mountain regions over arid Northwest China," Advances in Meteorology, vol. 2017, Article ID 4291765, 10 pages, 2017.

[38] B. Cao, B. Pan, J. Wang et al., "Changes in the glacier extent and surface elevation along the Ningchan and Shuiguan river source, eastern Qilian Mountains, China," Quaternary Research (United States), vol. 81, no. 3, pp. 531-537, 2014.

[39] L. Yan and M. Zheng, "The response of lake variations to climate change in the past forty years: A case study of the northeastern 
Tibetan Plateau and adjacent areas, China," Quaternary International, vol. 371, pp. 31-48, 2015.

[40] M. Xu, B. S. Ye, Q. Zhao, and J. Wang, "Spatiotemporal change of water reserves in the Tianshan Mountains, Xinjiang based on GRACE," Arid Zone Research, vol. 30, no. 3, 2013.

[41] K. Matsuo and K. Heki, "Time-variable ice loss in Asian high mountains from satellite gravimetry," Earth and Planetary Science Letters, vol. 290, no. 1-2, pp. 30-36, 2010.

[42] K. F. Zhao and X. Li, "Estimating terrestrial water storage changes in the Tarim River Basin using GRACE data," Geophysical Journal International, vol. 211, no. 3, pp. 1449-1460, 2017.

[43] L. Q. Xue, F. Yang, C. Yang et al., "Identification of potential impacts of climate change and anthropogenic activities on streamflow alterations in the Tarim River Basin, China," Scientific Reports, vol. 7, no. 1, article no. 8254, 2017.

[44] Y. Yu, R. Yu, X. Chen, G. Yu, M. Gan, and M. Disse, "Agricultural water allocation strategies along the oasis of Tarim River in Northwest China," Agricultural Water Management, vol. 187, pp. 24-36, 2017.

[45] Y. F. Shi, China's Glaciers And The Environment: Now, past And Future, Science Press, Beijing, China, 2000.

[46] H. Wang, Y. Chen, W. Li, and H. Deng, "Runoff responses to climate change in arid region of northwestern China during 1960-2010," Chinese Geographical Science, vol. 23, no. 3, pp. 286300, 2013.

[47] T. Yao, Y. Wang, S. Liu, J. Pu, Y. Shen, and A. Lu, "Recent glacial retreat in High Asia in China and its impact on water resource in Northwest China," Science China Earth Sciences, vol. 47, no. 12, pp. 1065-1075, 2004.

[48] Z. Ye, H. Liu, Y. Chen, S. Shu, Q. Wu, and S. Wang, "Analysis of water level variation of lakes and reservoirs in Xinjiang, China using ICESat laser altimetry data (2003-2009)," PLoS ONE, vol. 12, no. 9, Article ID e0183800, 2017. 

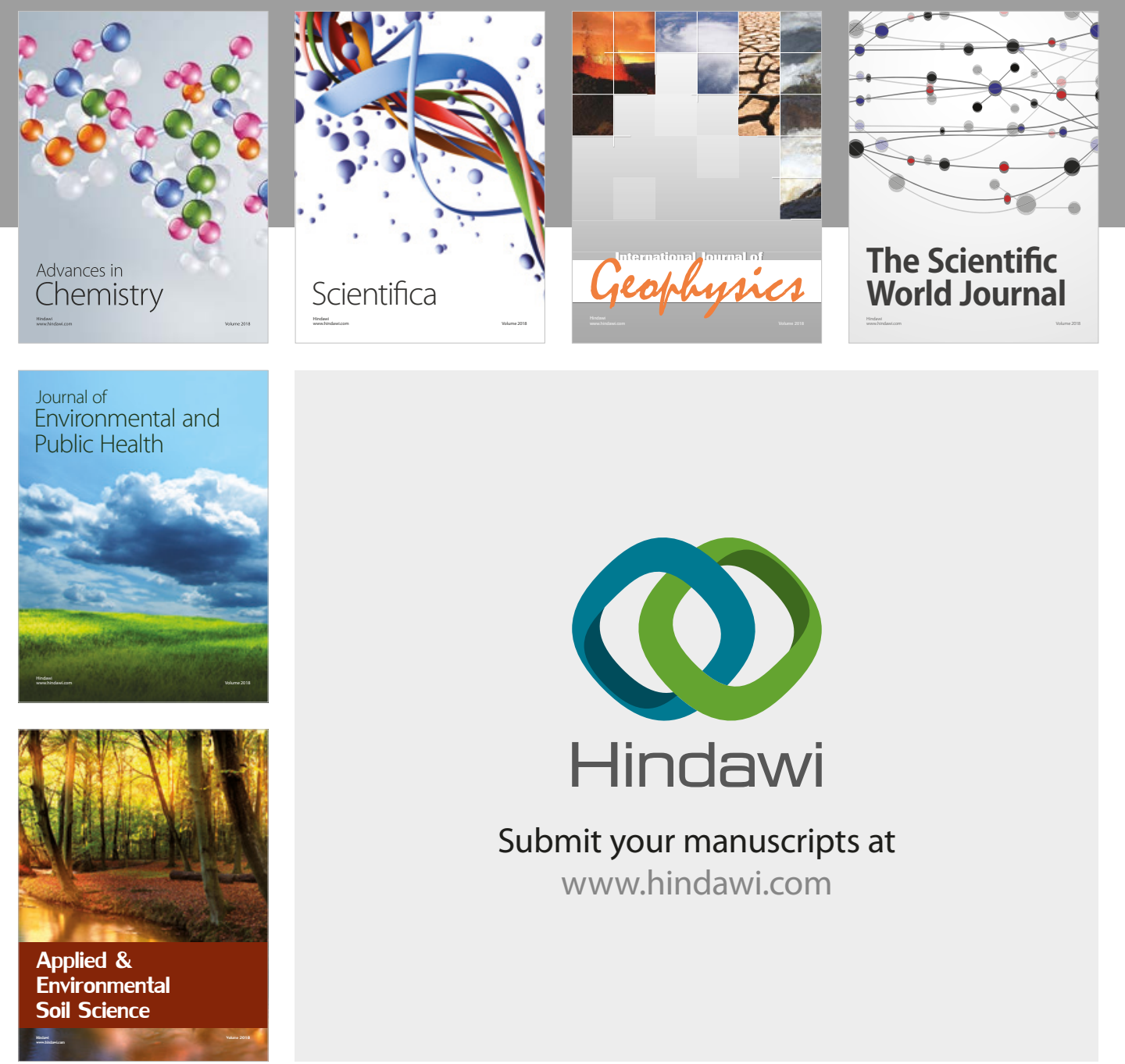

The Scientific

\section{World Journal}
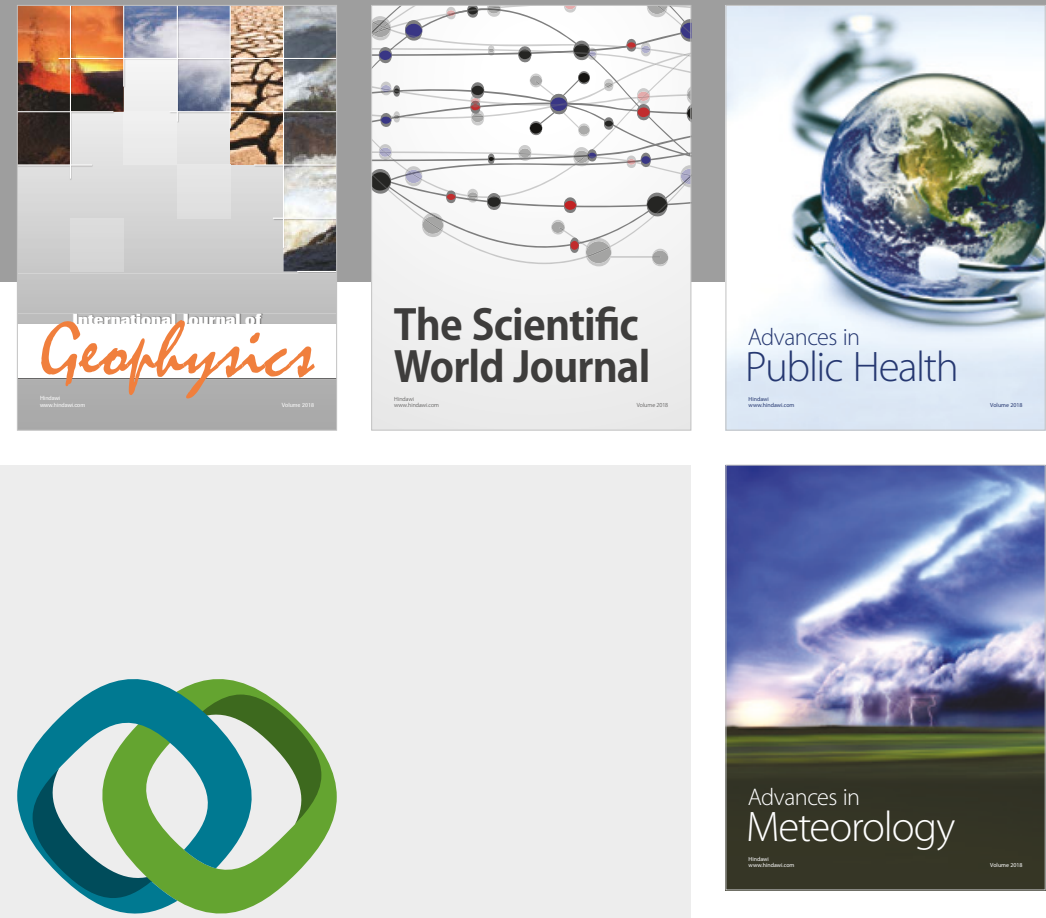

Advan

Public Health

\section{Hindawi}

Submit your manuscripts at

www.hindawi.com
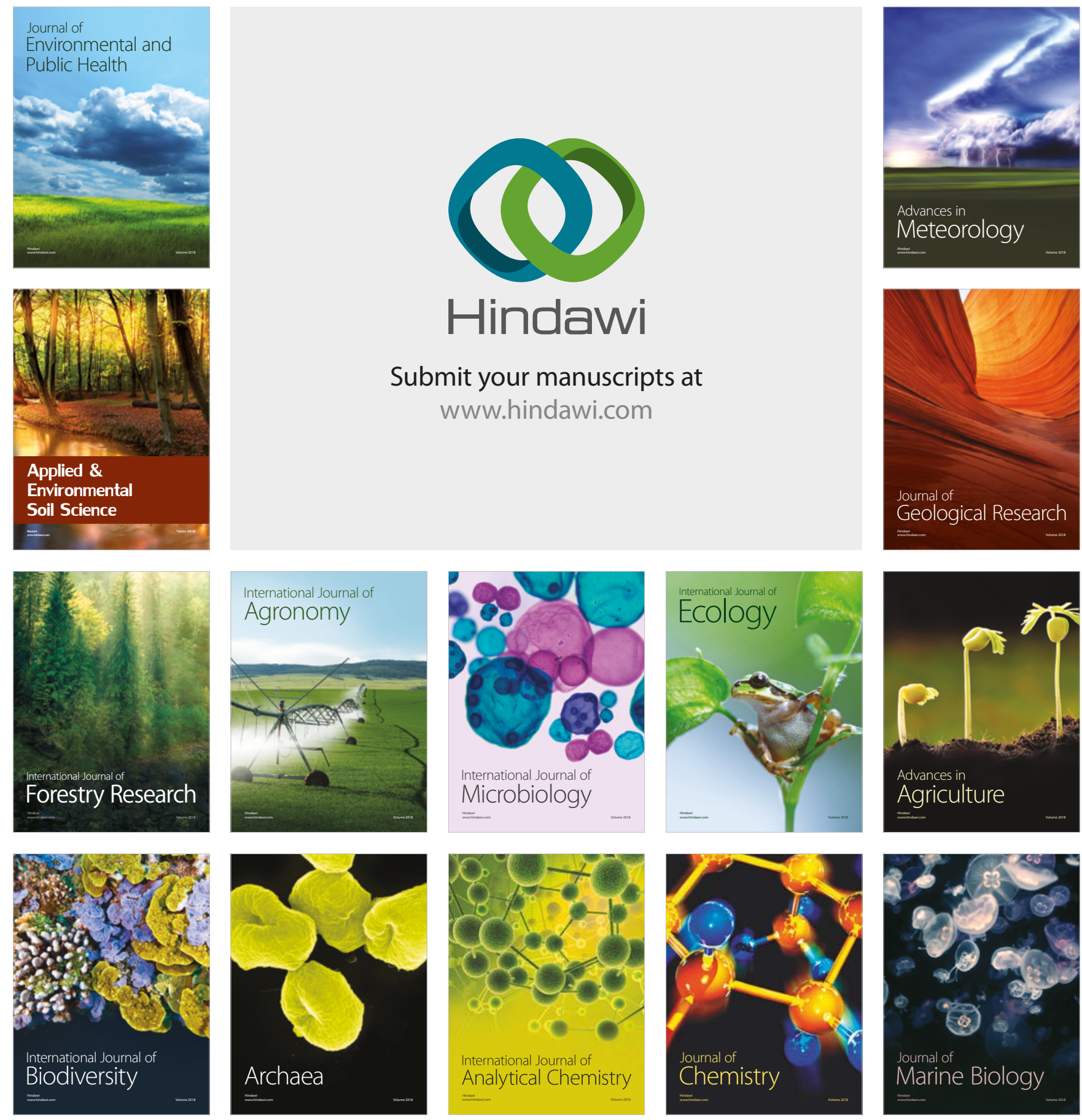